\title{
The future of technology and marketing: a multidisciplinary perspective
}

\author{
Dhruv Grewal $^{1}$ • John Hulland ${ }^{2}$ - Praveen K. Kopalle ${ }^{3}$ - Elena Karahanna ${ }^{2}$
}

Published online: 17 December 2019

(C) The Author(s) 2019

New technologies have revolutionized nearly every aspect of human existence, including the ways that firms market products and services to consumers. Along with now familiar innovations like the Internet, greater computing capacity, mobile devices and applications, and social media, more radical innovations are emerging. Related to artificial intelligence (AI) (Davenport 2018), the Internet of things (IoT) (Hoffman and Novak 2018), and robotics (Mende et al. 2019), these technological advances are exerting profound effects on the practice of marketing.

Thus, it should come as no surprise that firms across nearly every business sector (e.g., retailing, manufacturing, healthcare, financial) keep steadily increasing their technology spending, driven to reach various objectives. For example, many manufacturing firms seek cost savings through mechanized and robotic production processes, which both limit labor costs and increase production efficiencies. Retailers and service firms devote more spending to online, mobile, and social media platforms in attempts to better communicate and connect with customers (both current and potential), thereby increasing their revenues.

Dhruv Grewal

dgrewal@babson.edu

John Hulland

jhulland@uga.edu

Praveen K. Kopalle

kopalle@dartmouth.edu

Elena Karahanna

ekarah@uga.edu

1 Department of Marketing, Babson College, Babson Park, MA 02457, USA

2 Terry College of Business, University of Georgia, Athens, GA 30601, USA

3 Tuck School of Business, Dartmouth College, Hanover, NH 03755, USA
Early adopters of each new technology change the rules of the game (e.g., Grewal 2019). Consider Amazon as an example: It leads the pack in adopting a host of technological innovations. Its fulfillment centers feature robotic technologies to assist workers, increase efficiencies, and drive down costs. Amazon is actively experimenting with drone delivery (a service it calls Prime Air). Furthermore, it is known for its predictive analytic capabilities, uses AI to establish and maintain its sophisticated personalized recommendation system, and has developed an innovative, patented, one-click ordering system.

Ride-sharing firms like Uber and Lyft similarly have revolutionized traditional taxi and limousine industries, as well as providing novel work opportunities and greater customer control over their rides. Such groundbreaking shifts also depend heavily on the available technology, including geofencing and social media ratings capabilities. Newer options, such as autonomous vehicles, are on the horizon and likely to shake up the ride-sharing industry and ultimately the entire transportation industry. Waymo (Google's self-driving vehicle), Tesla, and Volvo are all racing to introduce the first driverless test vehicles to create value for consumers and business customers.

These technological innovations and the resulting applications and solutions, with their unprecedented effects and unfamiliar outcomes, compel marketers to get ahead of the knowledge curve. For example, it is important to establish the likely influences of new technologies on both firm strategies and consumer (and customer) behaviors. Furthermore, innovations emerging in technology, data storage, analytics, and solutions highlight opportunities for marketing practitioners to create, communicate, capture, and deliver value for and with their customers.

With these considerations in mind, we organized this special issue explicitly in an attempt to understand the future of technology and marketing. That is, this special issue explores in detail how technological innovations are likely to shape the practice and discipline of marketing for the next several 
decades. Furthermore, we recognize that marketing researchers need to engage in multidisciplinary collaborations with non-marketers to tackle the big challenges and opportunities that firms face when they try to harness the power of many new technologies. In putting this special issue together, we actively encouraged interdisciplinary submissions, and we were gratified to receive compelling, multidisciplinary insights from researchers working across the marketing, IT, and strategy domains.

The resulting collection of papers is organized into six broad, critical areas. Although they clearly cannot be comprehensive in terms of dealing with all cutting-edge technological innovation applications, these papers represent six significant and important areas of research (see Figure 1): health technology, AI and robotics, dark web and chatbots, mobile and social, in-store technology, and legacy technology.

With this introductory editorial, we apply these six themes to introduce the seven papers and two commentaries that constitute the special issue. In so doing, we outline our organizing framework and the various components in greater detail. We also offer some suggestions for additional research that use the contributions herein as a foundation.

\section{An overarching technology-marketing framework}

Building on studies of the impacts of technology on customers, employees, and firms (e.g., Parasuraman and Grewal 2000; Yadav and Pavlou 2014, 2020), Fig. 2 integrates the key

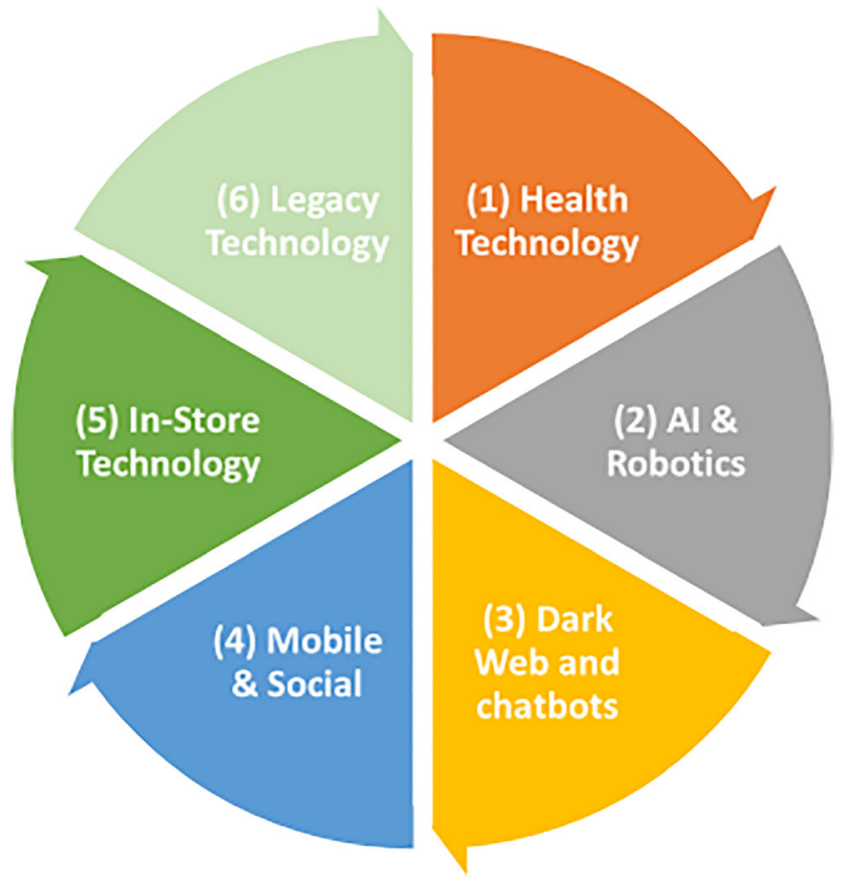

Fig. 1 The Future of Technology in Marketing elements of Fig. 1 to display how they influence both the benefits and costs associated with adopting novel technologies. As an integral component of the framework, we identify six technologies (defined in a broad sense, such that technology subsumes hardware, software, applications, and solutions). These themes often appear in different silos in a host of practitioner and academic publications, but they more accurately and effectively should be viewed as interconnected cogs of a broader firm strategy.

These technologies produce benefits (e.g., access to big data, improved customer experience management), but they also trigger concerns, such as those associated with information security and potential privacy risks. In the model, these intermediary effects of technology subsequently influence customer satisfaction/loyalty, employee well-being, firm profitability, and the ecosystem in which the firm's marketing activities are conducted. Considering these connections, we assert that firms must carefully develop and implement data collection efforts among customers, employees, and partners through technology-supported touchpoints, then leverage the technology benefits while minimizing the risks to guide their decision-making processes. We use our discussion of these six themes to introduce the articles and commentaries included in this special issue, as well as highlight how technology is shaping the future of marketing.

\section{Theme 1: Health technology}

Traditionally, marketing has not focused on healthcare, yet the healthcare field has a long tradition of leveraging and integrating data from multiple sources and using analytics to inform product offerings, recommendations, and the personalization of patient experiences to drive patient value. In this sense, the shifting healthcare landscape, fueled by technological advances and regulatory shifts, requires a marketing approach, as it transforms from a sector that has provided patient care using episodic and reactive measures to one that relies on continuous and proactive assessments, from reimbursementbased to evidence-based medicine, from rewarding volume to rewarding value (Burwell 2015), and from being providercentered to being patient-centered.

In these ongoing efforts to provide healthcare "that is respectful of and responsive to individual patient preferences, needs, and values, ... ensuring that patient values guide all clinical decisions" (Institute of Medicine 2001, p. 3), the consumerization process, as manifested in healthcare, relies heavily on the proliferation of IoT devices, sensors, wearables, social media, genomics, electronic health records (EHR), and mobile health applications. These technological advances create fundamental shifts in the healthcare landscape (Agarwal et al. 2010; Agarwal et al. 2020), changing the granularity, volume, velocity, and variety of patient and wellness data collected. In particular, they are changing what care gets 

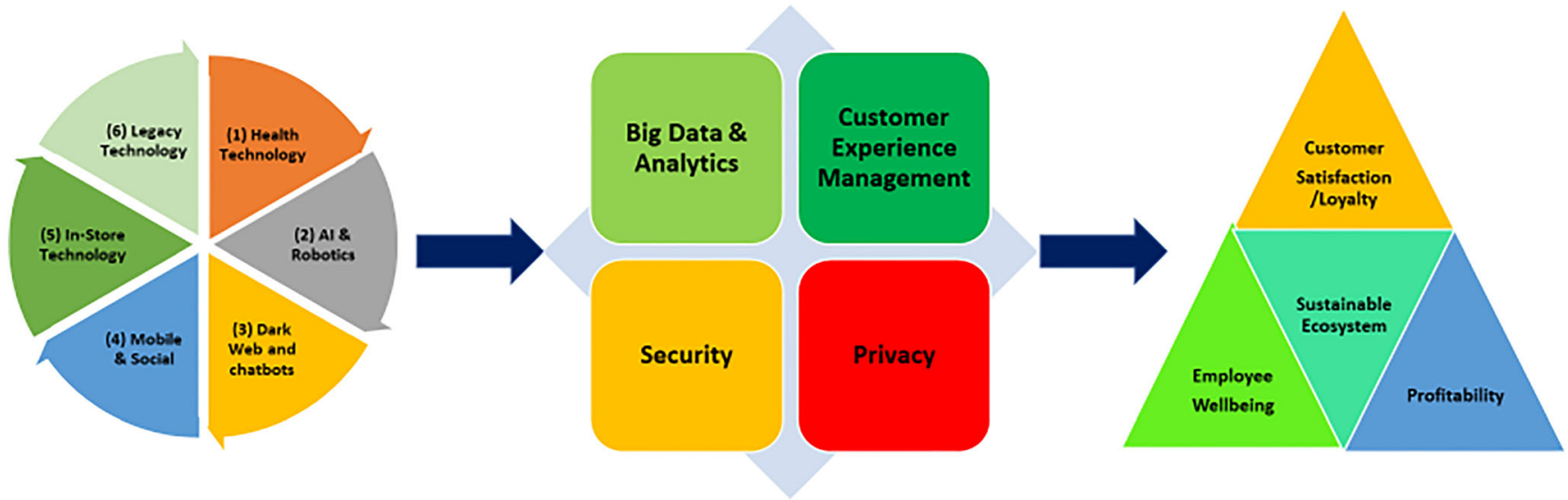

Fig. 2 Technology in Marketing

delivered (e.g., precision medicine), how and where care is delivered (e.g., remote monitoring), how patients interact with providers (e.g., patient portals, telemedicine), caregivers, and other patients (e.g., online patient communities), how patients receive medical information (e.g., conversational agents), and how organizations in the healthcare ecosystem exchange information and coordinate patient care.

For example, more than 318,000 mobile health apps provide information-from fitness and wellness suggestions to disease-specific insights (e.g., monitoring glucose levels for diabetic patients) to mobile medication reminders to interactions with medical providers - to an estimated three billion plus users worldwide (IQVIA Institute for Human Data Science 2017). The IoT also connects a vast range devices such as in-hospital medical devices, in-hospital and remote patient monitoring devices (e.g., Brohman et al. forthcoming), wearables (e.g., Jiang \& Cameron forthcoming; Lupton 2017), sensors that can detect potential falls, and ingestibles (e.g., pill cameras for imaging). These devices generate massive volumes of granular, real-time data to support ongoing analyses and interpretations, provide alerts, and enable effective interventions. In parallel, modern sensors can be carried, worn, or ingested, and their evolving capabilities include abilities to measure and record increasingly subtle signals, even passively; integrate with the web to share and access data; and aggregate and interpret information $\mathrm{AI}$.

In this issue, Agarwal et al. (2020) suggest that in this new landscape, patient needs and desires are increasingly prominent, because empowered patients and consumers reject roles as "captive recipients of healthcare products and services." The parallels to marketing appear clear, in accordance with calls to identify consumer preferences, personalize offerings, achieve satisfactory consumer experiences, and create and measure customer value. Agarwal et al. integrate marketing and healthcare research to propose a value-centered marketing (VCM) framework for healthcare with three core dimensions: preferences, precision, and process. The VCM requires biological, medical, behavioral, and contextual data, captured through patient touchpoints (EHR, social media, online health communities, sensors, wearables) and analyzed with AI. In turn, consumer decision-making theories and analytics can be adapted to help patients understand their risk preferences.

For example, marketing research pertaining to recommender systems might be leveraged to design techniques to help patients choose their treatment plans, by taking their risk and outcome preferences (e.g., quality of life vs. prolonging life for certain treatments) into account. Patient and wellness data also might inform predictive analytics so that providers can target specific segments with appropriate wellness, prevention, and treatment interventions, personalized according to genetic profiles, health conditions, predispositions, and risk factors. Another application might involve consumer churn models, which could be adapted to predict levels of adherence to treatments; social marketing techniques could inform the design of health campaigns. Because the consumer (patient) experience is an important outcome in its own right, healthcare researchers and professionals also can turn to theories pertaining to customer experience, customer engagement, and customer satisfaction to learn new ways to enhance their patients' experience.

Yet the use of technology to gather and store healthcare data, and then intervene in people's health-related decisions, also gives rise to relevant concerns, and several contributions in this special issue address those concerns. Ensuring the security and privacy of patient and wellness data is of utmost importance. Managing security and privacy risks while also eliciting and leveraging data to enable personalized recommendations and experiences is a constant tension, discussed extensively by Thomaz et al. (2020). In addition, Rai (2020) discusses that if patients are to trust and rely on personalized recommendations, explaining why these recommendations are made is critical (i.e., providing more visibility into the AI algorithm), especially for recommendations that are consequential to their health. Moreover, the benefits associated with using technology can lead to a wider digital divide with 
respect to vulnerable populations (e.g., elderly, residents of rural areas, minority groups). Whether due to access or ability to use technology, this divide implies that some groups do not benefit from advanced technologies and instead experience worsened health disparities, with troubling ethical consequences (Agarwal et al. 2020). Excluding vulnerable populations from data generation processes also will induce algorithmic biases, especially for diseases and conditions that manifest differently in various populations. Such biases and their potential remedies are the focus of the paper by Davenport et al. (2020), as detailed next.

\section{Theme 2: Al and robotics}

As noted earlier, $\mathrm{AI}$ is gaining greater power to address marketing and business challenges, across a vast number of usage contexts, including not just healthcare but also driverless cars (e.g., Tesla, Waymo), retailing, customer service (e.g., the Pepper robot), and so forth (see Table 1 in Davenport et al. 2020). To facilitate our understanding of these developments, Davenport et al. (2020) present an AI framework that highlights its use for task automation in the short and medium turn, mostly for standardized, rule-based tasks (Davenport and Kirby 2016; Davenport and Ronanki 2018). In the longer term, AI also has the potential to achieve context awareness, by "learning to learn" and going beyond its initial programming. Context-aware AI solutions promise to be game changers, able to complete idiosyncratic tasks using adaptive, holistic, context-specific responses (Huang and Rust 2018). Such context awareness "constitutes the goal of AI developments, as predicted by compelling examples from science fiction, such as Jarvis from the Iron Man movies or Karen from Spider Man-Homecoming ... AI can understand new and complex contexts and create solutions therein" (Davenport et al. 2020). These different AI solutions include combined analyses of numbers, text, voice, faces, and images.

Moreover, AI can take either digital or robotic forms. Robotics is just starting to attract substantial research attention in the marketing field (van Doorn et al. 2017), and studies note the need to consider whether robots should look like machines or instead take anthropomorphized forms, such that they resemble humans (Thomaz et al. 2020). Mende et al. (2019) demonstrate empirically that humanized robots can evoke a sense of eeriness (in line with the "uncanny valley" notion) that then prompts greater compensatory behaviors, such as eating more to cope with the unpleasant sensation. Thus, they call on robotic designers to think more carefully about the form of the robots, as well as determining when humanoid robots are likely to lead to ready acceptance or not. This research line remains underdeveloped, indicating the need for more studies about how, when, and where robots can effectively and meaningfully enhance customer experiences.
In addition, because $\mathrm{AI}$ and machine learning solutions are only as good as the training data and models that underlie them, we need constantly updated insights into optimal ways to leverage big data and advanced analytics capabilities. Personalization strategies can benefit from such technologies, such that new marketing campaigns can integrate information gathered from household appliances, robotic assistants, biometric sensors, and real-time usage data across digital ecosystems. Furthermore, explainable AI (XAI) help users gain greater visibility into the black box and how the AI-based recommendations are being made (Rai 2020). Therefore, XAI can encourage customer engagement and actions and increase trust and visibility into the underlying decisionmaking processes, detect algorithm bias, and ultimately reduce litigation. Which marketing AI applications, and under what conditions, can benefit from the range of explainable AI (XAI) techniques that make $\mathrm{AI}$ recommendations and actions more transparent is an open question.

But the "big data revolution," just like any revolution, may sow some discontent, especially in relation to data security. In this sense, the goal should not be bigger data but instead better data, informed by both the science of machine learning, robotics, and AI and the art of marketing and creativity. Consider predictive analytics as an example. It begins with data, which today are massive and high in velocity, including tweets, blogs, loyalty card transactions, eye-tracking, and so forth. Using tools such as Bayesian inference, marketers can observe billions of page views, then creatively apply the insights they gain from these big data to estimate people's price sensitivity, product preferences, or likely next steps on the customer journey. These developments in customer, data, and marketing practices provide tremendous opportunities to grant customers better, more seamless experiences, but also risks associated with data security and privacy.

\section{Theme 3: The dark web and chatbots}

In the past two decades, consumers have expressed growing concern about data privacy, particularly in terms of their (in)ability to control the kinds of personal information that are collected about them (Pew Research Center 2014) or shared with others (Martin and Murphy 2017). A growing momentum thus moves toward a view of privacy as a fundamental human right, leading both firms and governments to consider potential mechanisms to address these needs, such as laws that restrict firms' access to customer data (e.g., the European Union's General Data Protection Act, California's AB 375 bill). From a marketing perspective, firms then need to find an appropriate balance between managing consumers' privacy concerns while also using consumer data to deliver personalized products and services (Martin and Murphy 2017). Many consumers remain unaware of the true value of their personal data, so they offer it to firms at little or no cost; 
even consumers who exhibit greater awareness still tend to be willing to exchange privacy for personalized offerings if they trust the marketer. This complex trade-off is known as the personalization-privacy paradox (Aguirre et al. 2015, 2016; Bleier and Eisenbeiss 2015).

Technology can play a prominent role in determining (and potentially resolving) this trade-off. As Agarwal et al. (2020) propose in this issue, healthcare organizations may be able to use technology-driven privacy protection initiatives to build trust with customers. Appel et al. (2020) suggest social media as a potential tool to engender greater consumer trust regarding the use of their private information. Thomaz et al. (2020) instead propose that anthropomorphized technology offers the potential to nudge consumers toward greater self-disclosure, because it transmits social cues that activate social scripts, and its conversations invoke norms of reciprocity (Moon 2000).

Yet even as these developments expand, the shift toward individual consumer privacy appears likely to continue. In their paper, Thomaz et al. (2020) argue that a web-wide, hyper-private future may come to mirror practices currently observed in the Dark Web. The Dark Web has gained notoriety, following revelations of its use for hidden criminal activity and black markets (e.g., Silk Road marketplace), whistleblowing (Wikileaks), and protecting activists (e.g., Arab Spring). Dark Web participants use every possible means, from technological to behavioral, to minimize their digital footprints, which means very little information about them is visible or available to other parties, unless they choose to disclose it. Over time, these practices are likely to spread to the conventional or Surface Web, which incorporates all websites indexed by search engines, such that they are easily navigable. For example, Firefox has adopted an antifingerprinting measure to increase user privacy and circumvent online advertising, and WhatsApp offers a dark web-like experience by enabling users to hide the contents of their hyper-private communications even from the service provider.

Firms that seek to adapt to this new hyper-private environment need to understand how to use consumer-facing technologies to generate value and tip consumers' privacy trade-off toward greater data sharing. That is, the ability to collect identifiable data becomes particularly important when web platforms offer users more options to keep their browsing activity private (Bursztein 2017). Conversational agents (CAs), also known as chatbots, could be critical in this effort, especially as front-facing service representatives. They can enhance both the experience and the outcomes of consumer interactions, across sales, marketing, and customer service functions (Daugherty and Wilson 2018). As CAS make it easier for consumers to access data, evaluate information, and take actions, they can nudge consumers to share more personal data. Successful CAs should be designed to engage and personalize the consumer experience. Companies that motivate and nudge consumers to self-disclose their private data, whether in interactions with CAs or otherwise, will have a clear competitive edge.

\section{Theme 4: Mobile and social}

The introduction of smart phones has completely altered how most consumers go about their daily routines. For example, many consumers look at their smart phones immediately upon waking, because they have set their alarms on those devices. Then, phones already in hand, they review their text messages, social media streams, the daily news, and e-mails, often before they even get out of their bed. Throughout the day, people interact nearly constantly with their mobile devices (and the apps supported by them) (Grewal et al. 2018), using them as a gateway to social media, reading information, viewing ads, posting information, commenting, liking, and sharing a host of information. They also interact with various firms through the mobile apps that they have downloaded or through web browsers, and during these interactions, they engage in all kinds of transactions such as ordering food through Uber Eats, paying bills, buying merchandise on Amazon, making travel reservations, viewing health test results, or buying stock.

Tong et al. (2020) detail how the growth in mobile technology, apps, and data has paved the way for more personalized mobile marketing strategies. The authors propose a $5 \mathrm{P}$ model of the personalized marketing mix, comprised of mobile products, mobile promotions, mobile place, mobile price, and mobile predictions. On the basis of their illustrative review of these five components, the authors derive key issues that warrant further research, such as the need to understand how consumers respond to promotions that they receive while they are located in an unpleasant setting (e.g., traffic jam, polluted environment). The suggested research issues emphasize the importance of contextual factors for defining and developing effective mobile marketing strategies.

Moreover, consumers use mobile phones to engage with both firms and social media, and as Grewal and Stephen (2019) find, consumers view reviews posted from a mobile device differently than those posted via a desktop computer. Appel et al. (2020) offer new insights into the complex, multifaceted questions surrounding how reviews and social media influence consumer behavior, by proposing nine social media themes organized into two factors: predicted imminence (the immediate future, the near future, or the far future) and focal stakeholders (individuals, firms, or public policy). Some of these important themes reflect key public policy issues, namely, privacy, social media as a political tool, and social media content created by non-humans. All of these themes are likely to have far-reaching importance in coming years, for elections, human interactions, and the use of bots. 
We add to these suggestions by calling for research addressing issues such as the role of who posts the content (firm vs. customer) and the effects of different types of posted content (e.g., social media post or review). Both social media updates and consumer reviews can influence consumer behavior, but it important to compare these effects and specify when one type might be more effective than the other. Further insights might be gained by investigating whether the different types have distinct effects at various stages in the customer journey; perhaps reviews are more beneficial in the information search and evaluation stages, but posts could be more useful in the need recognition stage. Then in later stages, firms should determine with whom consumers are engaging with if they decide to respond to a post. Should the primary concern be the individual poster, or should their focus be the effects on other readers who witness the exchange on social media platforms (Herhausen et al. 2019)? It is possible that the response strategies might differ, depending on the firm's priorities.

\section{Theme 5: In-store retail technology}

Retailing and services industries already have adopted some truly advanced in-store and online technologies to serve their customers (Grewal et al. 2017), whether by facilitating the shopping process or helping customers move through each stage of their customer journey. Firms in these industries also capitalize on their access to big data by steadily developing their analytical and predictive capabilities (Bradlow et al. 2017). In this special issue, Grewal et al. (2020) also address advances in in-store technologies, which they classify according to whether they provide convenience (high vs. low) and social presence (high vs. low). In this $2 \times 2$ framework, instore technologies that rank high in both customer convenience and social presence include augmented reality, virtual reality, embodied robots, avatars, and smart displays. For example, Sephora uses augmented reality technology to allow customers to try products, take pictures of themselves, and post and share the content (Sephora 2018). Rebecca Minkoff stores have installed smart mirrors in dressing rooms, so customers can see various products, accessorize their looks, and engage with sales associates (Grosman 2017). Because these technologies enhance the vividness of available products and the customer experience, they likely influence and encourage shopping behaviors.

An interesting element of these various convenience and social presence technologies is their promise to help brickand-mortar retailers compete more effectively with online retailers and the likes of Amazon. The challenges presented by Amazon for conventional retailers are constant, broad-based, and steadily increasing; Amazon dominates a vast range of categories, and as it expands its store brand offerings, it creates new challenges for manufacturers and name brands, as well as other retailers. But in-store technologies might suggest some win-win opportunities for manufacturers and retailers that want to enhance their customers' in-store shopping experiences and thereby encourage more sales and higher profits.

\section{Theme 6: Legacy technologies}

Although the significance and power of digital titansUber, Google, Netflix, Alibaba, and Amazon, to name a few-primarily derives from their ability to harness customer information through modern digital technologies, access to such technologies is not limited to these influential firms. That is, Netflix might have demolished Blockbuster; Alibaba, Tencent, and Baidu might be issuing credible threats to traditional banks; and Amazon might have revolutionized businesses in a vast range of sectors, including supermarkets, publishing, and logistics. They have done so by gathering and leveraging information to enhance customer experiences. But virtually any legacy business arguably can make use of similar digital technologies to transform their approaches, offerings, and customer orientations. So why do so few firms actually adopt sensors, the IoT, or AI in their regular practices?

Kopalle et al. (2020) in this issue, argue that a key reason is their failure to recognize the emergence of digital customers and the power of a digital customer orientation. That is, legacy firms often struggle to recognize understand an essential trait of digital customers: They provide in-use information while consuming a product or service. Therefore, the authors propose the need for a digital customer orientation from the firm, such that it channels product in-use information to expand the customer experiences, on the dimensions that customers value, using the digital information. The following example illustrates the product in-use information notion: Apple Watch wearers might receive early notice of cardiac arrest, with sufficient lead time available to drive themselves (or have their self-driving cars take them) to the hospital. The framework that Kopalle et al. (2020) propose aims to help legacy firms marshal modern digital technologies, to pivot from physical to digital customers and to create new digital customer orientation capabilities, both of which are necessary to undertake a digital transformation.

\section{Conclusion}

In conclusion, we believe this interdisciplinary special issue, focusing on the future of technology and marketing, will spur continued research on the important issues outlined in the included seven articles and two commentaries. Researchers addressing these issues can benefit from working in interdisciplinary teams, enabling them to tackle complex problems in conjunction with (and the assistance of) other stakeholders, such as industry 
representatives, firms, government, and nonprofit organizations. Moreover, research in these domains needs to establish both the fundamental effects of various technologies (e.g., AI, robotics, IoT, sensors, augmented technology) and insights into the underlying processes that explain the (customer and employee) behavioral consequences of using the technologies in a variety of contexts (e.g., retail, health service, ride sharing). Finally, identifying factors that moderate these effects can provide more clarity with regard to when the outcomes might be augmented or mitigated, in ways both beneficial and potentially detrimental.

In addition to expressing these hopes for continued development of the field, we express our deep appreciation to the authors who submitted their work for criticism and consideration, as well as to the reviewers who devoted substantial time and effort to ensuring the high quality and relevance of the included articles. The reviewers are listed in the Appendix; we are indebted to them for their intellectual contributions.

\section{Appendix}

\section{Special issue reviewers}

We express our deep appreciation to reviewers who devoted substantial time and effort to ensuring the high quality and relevance of the included articles.

- Dhruv Grewal, John Hulland, \& Praveen Kopalle, \& Elena Karahanna.

Special Issue Guest Editors.

\begin{tabular}{ll}
\hline Reviewer Name & Reviewer University \\
\hline Yakov Bart & Northeastern University \\
Mark Houston & Texas Christian University \\
Ming-Hui Huang & National Taiwan University \\
Martin Mende & Florida State University \\
Vikas Mittal & Rice University \\
Satish Jayachandran & University of South Carolina \\
Stephan Ludwig & University of Melbourne \\
Xueming Luo & Temple University \\
Robert Palmatier & University of Washington \\
Andrew J. Petersen & Penn State University \\
Venkatesh Shankar & Texas A\&M University \\
Maura Scott & Florida State University \\
Sridhar Shrihari & Texas A\&M University \\
Martin Wetzel & Maastricht University \\
\hline
\end{tabular}

Open Access This article is distributed under the terms of the Creative Commons Attribution 4.0 International License (http:// creativecommons.org/licenses/by/4.0/), which permits unrestricted use, distribution, and reproduction in any medium, provided you give appropriate credit to the original author(s) and the source, provide a link to the Creative Commons license, and indicate if changes were made.

\section{References}

Agarwal, R., Gao, G., DesRoches, C., \& Jha, A. K. (2010). Research commentary-The digital transformation of healthcare: Current status and the road ahead. Information Systems Research, 21(4), 796809.

Agarwal, R., Dugas, M., Gao, G., \& Kannan, P. K. (2020). Emerging technologies and analytics for a new era of value-centered marketing in healthcare. Journal of the Academy of Marketing Science, 48(1), https://doi.org/10.1007/s11747-019-00692-4.

Aguirre, E., Mahr, D., Grewal, D., de Ruyter, K., \& Wetzels, M. (2015). Unraveling the personalization paradox: The effect of information collection and trust-building strategies on online advertisement effectiveness. Journal of Retailing, 91(1), 34-49.

Aguirre, E., Roggeveen, A. L., Grewal, D., \& Wetzels, M. (2016). The personalization-privacy paradox: Implications for new media. Journal of Consumer Marketing, 33(2), 98-110.

Appel, G., Grewal, L., Hadi, R., \& Stephen, A. T. (2020). The future of social media in marketing. Journal of the Academy of Marketing Science, 48(1), https://doi.org/10.1007/s11747-019-00695-1.

Bleier, A., \& Eisenbeiss, M. (2015). The importance of trust for personalized online advertising. Journal of Retailing, 91(3), 390-409.

Brohman, K., Addas, S., Dixon, J., \& Pinsonneault, A. (forthcoming). Cascading feedback: A longitudinal study of a feedback ecosystem for Telemonitoring patients with chronic disease. MIS Quarterly.

Burwell, S. M. (2015). Setting value-based payment goals - HHS efforts to improve U.S. health care. The New England Journal of Medicine, 372(10), 897-899.

Bursztein, E. (2017). Understanding how people use private browsing. Retrieved February 6, 2019, from Elie Bursztein's site website: https://www.elie.net/blog/privacy /understanding-how-people-useprivate-browsing.

Bradlow, E. T., Gangwar, M., Kopalle, P., \& Voleti, S. (2017). The role of big data and predictive analytics in retailing. Journal of Retailing, 93, 79-95.

Daugherty, P. R., \& Wilson, H. J. (2018). Human + machine: Reimagining work in the age of AI. Retrieved from http://public. eblib.com/choice/publicfullrecord.aspx? $\mathrm{p}=5180063$.

Davenport, T. H. (2018). The AI advantage: How to put the artificial intelligence revolution to work. Cambridge: MIT Press.

Davenport, T., Guha, A., Grewal, D., \& Bressgott, T. (2020). How artificial intelligence will change the future of marketing. Journal of the Academy of Marketing Science, 48(1), https://doi.org/10.1007/ s11747-019-00696-0.

Davenport, T. H., \& Kirby, J. (2016). Just how smart are smart machines? MIT Sloan Management Review, 57(3), 21-25.

Davenport, T. H., \& Ronanki, R. (2018). Artificial intelligence for the real world. Harvard Business Review, 96(1), 108-116.

Grewal, D. (2019). Retail marketing management: The 5 Es of retailing. London: Sage Publications.

Grewal, D., Noble, S. M., Roggeveen, A. L., \& Nordfält, J. (2020). The future of in-store technology. Journal of the Academy of Marketing Science, 48(1), https://doi.org/10.1007/s11747-019-00697-z.

Grewal, D., Roggeveen, A. L., \& Nordfält, J. (2017). The future of retailing. Journal of Retailing, 93, 1-6. 
Grewal, D., Ahlbom, C. P., Beitelspacher, L., Noble, S. M., \& Nordfält, J. (2018). In-store mobile phone use and customer shopping behavior: Evidence from the field. Journal of Marketing, 82, 102-126.

Grewal, L., \& Stephen, A. T. (2019). In Mobile we trust: The effects of Mobile versus nonmobile reviews on consumer purchase intentions. Journal of Marketing Research, 56(5), 791-808.

Grosman, L. (2017). The future of retail: How we'll be shopping in 10 Years. Retrieved October 2, 2019 from https://www.forbes.com/ sites/forbescommunicationscouncil/2017/06/20/the-future-of-retailhow-well-be-shopping-in-10-years/\#21188bbe58a6

Herhausen, D., Ludwig, S., Grewal, D., Wulf, J., \& Schoegel, M. (2019). Detecting, preventing, and mitigating online firestorms in brand communities. Journal of Marketing, 83(3), 1-21.

Hoffman, D. L., \& Novak, T. P. (2018). Consumer and object experience in the internet of things: An assemblage theory approach. Journal of Consumer Research, 44(6), 1178-1204.

Huang, M. H., \& Rust, R. T. (2018). Artificial intelligence in service. Journal of Service Research, 21(2), 155-172.

Institute of Medicine (IOM) (2001). Crossing the quality chasm (brief report). Washington, DC: National Academy Press, http://www. nap.edu/html/quality_chasm/reportbrief.pdf

IQVIA Institute for Human Data Science. (2017). The growing value of digital health: Evidence and impact on human health and the healthcare system. Retrieved September 18, 2018, from https:// www.iqvia.com/institute/reports/the-growing-value-of-digitalhealth

Jiang, J., \& Cameron, A. F. (forthcoming). IT-enabled self-monitoring for chronic disease self-management: An interdisciplinary review. MIS Quarterly.

Kopalle, P. K., Kumar, V., \& Subramaniam, M. (2020). How legacy firms can embrace the digital ecosystem via digital customer orientation. Journal of the Academy of Marketing Science, 48(1), https://doi.org/ 10.1007/s11747-019-00694-2.

Lupton, D. (2017). The quantified self. Cambridge: Polity Press.

Martin, K. D., \& Murphy, P. E. (2017). The role of data privacy in marketing. Journal of the Academy of Marketing Science, 45(2), $135-155$.

Mende, M., Scott, M. L., van Doorn, J., Grewal, D., \& Shanks, I. (2019). Service robots rising: How humanoid robots influence service experiences and food consumption. Journal of Marketing Research, $56(4), 535-556$.
Moon, Y. (2000). Intimate exchanges: Using computers to elicit selfdisclosure from consumers. Journal of Consumer Research, 26(4), 323-339.

Parasuraman, A., \& Grewal, D. (2000). The impact of technology on the quality-value-loyalty chain: A research agenda. Journal of the Academy of Marketing Science, 28, 168-174.

Pew Research Center (2014). Public perceptions of privacy and security in the post-Snowden era. Retrieved, October 13, 2019, from http:// www.pewinternet.org/2014/11/12/public-privacy-perceptions/.

Rai, A. (2020). Explainable AI: From black box to glass box. Journal of the Academy of Marketing Science, 48(1), https://doi.org/10.1007/ s11747-019-00710-5.

Sephora (2018). Retrieved October 2, 2019 from https:// sephoravirtualartist.com/landing_5.0.php?country=US\&lang= en $\& \mathrm{x}=\&$ skintone $=\&$ currentModel

Thomaz, F., Salge, C., Karahanna, E., \& Hulland, J. (2020). Learning from the dark web: Leveraging conversational agents in the era of hyper-privacy to enhance marketing. Journal of the Academy of Marketing Science, 48(1), https://doi.org/10.1007/s11747-01900704-3.

Tong, S., Luo, X., \& Xu, B. (2020). Personalized mobile marketing strategies. Journal of the Academy of Marketing Science, 48(1), https:// doi.org/10.1007/s11747-019-00693-3.

van Doorn, J., Mende, M., Noble, S. M., Hulland, J., Ostrom, A. L., Grewal, D., \& Petersen, A. A. J. (2017). Domo Arigato Mr. Roboto: Emergence of automated social presence in organizational frontlines and customers' service experiences. Journal of Service Research, 20, 43-58.

Yadav, M. S., \& Pavlou, P. A. (2014). Marketing in computer-mediated environments: Research synthesis and new directions. Journal of Marketing, 78, 20-40.

Yadav, M. S., \& Pavlou, P. A. (2020). Interactions in digital environments: A Conceptual Foundation for current and future research. Journal of the Academy of Marketing Science, 48(1), https://doi. org/10.1007/s11747-019-00712-3.

Publisher's note Springer Nature remains neutral with regard to jurisdictional claims in published maps and institutional affiliations. 